\title{
Effect of genetic counselling on the prevalence of Huntington's chorea
}

\author{
CEDRIC O CARTER， KATHLEEN A EVANS， MICHAEL BARAITSER
}

\begin{abstract}
The relative fertility of sons and daughters of patients with Huntington's chorea was found to be a little under 0.5 if they had been told of their risk of transmitting the disease before they had started their families. The effect was much the same in those who had attended the genetic clinic at The Hospital for Sick Children on a single occasion and those who had been told of their risk directly, or indirectly through the patient's spouse or family doctor, by the neurologist who was looking after their affected parent at the National Hospital for Nervous Diseases.

If all offspring of patients were informed of their risk the effect on the prevalence of the disorder would be substantial, especially if the mutation rate is low and the reproductive fitness of patients in the past has been close to 1.0. Men and women at risk of developing the disease should not be seen on just one occasion, however: they need continued support by being seen regularly at a special neurological genetic clinic.
\end{abstract}

\section{Introduction}

In most serious genetic disorders with dominant transmission the affected families have fewer children than average. ${ }^{1}$ This trend is not seen in families with Huntington's chorea, in which the frequency at birth of children who will later develop the disorder is high. Nevertheless, the birth frequency of heterozygotes within families at risk, and hence the future prevalence of the disorder, may be reduced by an intensive programme of ascertainment of all cases in the region and annual visits to the families to confirm the non-directive genetic counselling and to provide practical help and moral support. ${ }^{2}{ }^{3}$ Such an intensive approach needs special funding and staff. What, however, may be achieved by simple genetic counselling, usually on one occasion, as part of the ordinary health service neurology and genetic clinics?

In 1979 we reported briefly ${ }^{4}$ a follow-up of young adults who knew that they had a parent with Huntington's chorea and had been seen at the genetic clinic at The Hospital for Sick Children before they had had children. We have now extended this earlier study. In addition, since a sample attending a genetic clinic might be somewhat atypical, we have studied the fertility of a

MRC Clinical Genetics Unit, Institute of Child Health, London WC1N 1EH

CEDRIC O CARTER, DM, FRCP, professor of clinical genetics

KATHLEEN A EVANS, AIMSW, social worker

The Hospital for Sick Children, London WC1N 3JH

MICHAEL BARAITSER, MB, FRCP, consultant clinical geneticist series of adults, each of whom had an affected parent who was a patient at the National Hospital for Nervous Diseases and each of whom had been told of their risk before they had planned their families. They had been warned of their risk by the neurologist in charge of the patient either directly or, more often, through the unaffected parent or the family doctor or by referral to a genetic clinic. Finally, we used the series of patients at the National Hospital to examine the fertility of patients who had not been warned of their risk before they completed their families.

\section{Material and methods}

Thirty seven individuals had attended the genetic clinic at The Hospital for Sick Children between 1966 and 1975 because they had a parent with confirmed Huntington's chorea. After tracing the current address and checking that the family doctor did not advise against an approach we wrote to them asking if we might visit. Two were not traced, one did not wish to be visited, and the remaining 34 were visited in their home (by KAE). Twenty one of the 34 had had no children at the time they came to the clinic and learnt of, or had confirmed, their 1 in 2 risk of inheriting the disease and their 1 in 4 risk of transmitting the disease to a particular child. The other 13 had started their families before they came to the clinic.

The records of the National Hospital produced 77 patients with a firm diagnosis of Huntington's chorea who had attended between 1966 and 1975. After tracing, checking with the consultants and the family doctor, and writing to the families of the patients (usually the spouse or a child), 47 families were visited ( 24 mostly born before 1920 were not traced, three did not wish to be visited, and in three cases the family doctor or consultant advised us not to visit). At this visit we determined the fertility of the children of the patients and the children's knowledge of their risk of transmitting the illness to their own children. In 25 of the remaining 30 patients sufficient information was available from the records and the family doctors to determine their own fertility but not that of their children.

The fertility of patients and the children (aged over 18) of patients was compared with that of the general population of England and Wales of the same age, the same sex, and born in the same year taken from table 10.7 in Birth Statistics $1979^{5}$ for the women born after 1919. For those born earlier than 1920 , table I(i) from the 1961 Census, ${ }^{6}$ which gives the mean family size of ever-married women, was used, with a correction for the proportion unmarried given in table 1.1 from Marriage and Divorce Statistics $1974 .^{7}$ The assumption was made that women would be on average two years younger than their husbands.

Only one child of a patient at the National Hospital was also a consultand at the genetic clinic in the period surveyed; he is included in both series and had no children.

\section{Results and comment}

The fertility of the children of patients who knew of their risk before they started their families is shown in table I separately by sex, and separately for the genetic clinic consultands and the children of the National Hospital patients. The fertility of the two groups is 
similar, and the women were a little more fertile than the men. Overall the relative fertility was 0.47 -that is, a little under a half that of the general population. Table II shows the fertility of the children who did not know of their risk before they started their families. The relative fertility is, as might be expected, higher, but still less than one. None of these genetic clinic consultands who already had children had had, or planned to have, further children once they had learnt at the clinic of their risk.

TABLE I-Fertility $(O)$ of children of patients who knew of their own risk befor starting their families compared with that $(E)$ of the general population

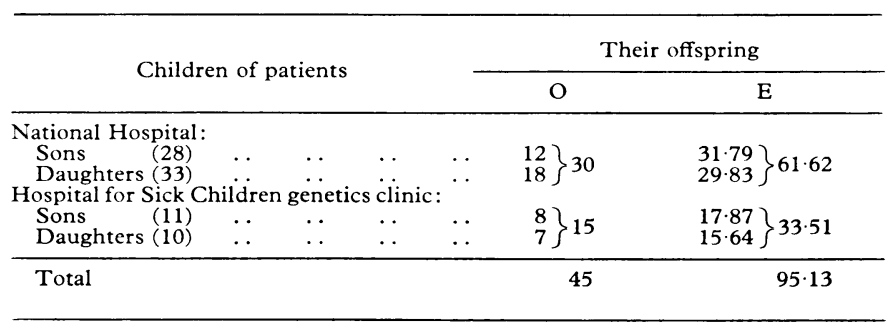

TABLE II-Fertility $(O)$ of children of patients who did not know of their risk before they started their families compared with that $(E)$ of the general population

\begin{tabular}{llc}
\hline \multirow{2}{*}{ Children of patients } & \multicolumn{2}{c}{ Their offspring } \\
\cline { 2 - 3 } & O & E \\
\hline National Hospital $(n=17)$ & 17 & $19 \cdot 82$ \\
Hospital for Sick Children $(n=13)$ & 22 & $25 \cdot 27$ \\
\hline Total & 39 & $45 \cdot 09$ \\
\hline
\end{tabular}

Table III shows the fertility of patients from the National Hospital who did not know of their risk before they had completed their families, with distinction of sex. Overall the relative fertility is close to 1.0 ; as in most series, however, the affected women have had more children per head than the men. The fertility of the nine patients who did know of their risk before they had started a family was low. They had had only three children when the expected number was 16.9. Several of these patients had had an early onset of the disease.

TABLE III-Fertility $(O)$ of patients who did not know of their risk before they had started their families compared with that $(E)$ of the general population

\begin{tabular}{lcc}
\hline \multirow{2}{*}{ Patients } & \multicolumn{2}{c}{ Their children } \\
\cline { 2 - 3 } & $\mathrm{O}$ & $\mathrm{E}$ \\
\hline Male $(\mathrm{n}=35)$ & 75 & 71.97 \\
Female $(\mathrm{n}=28)$ & 52 & 56.07 \\
\hline Total & 127 & 128.04 \\
\hline
\end{tabular}

\section{Discussion}

Harper and colleagues ${ }^{2}$ did not directly estimate the fertility of the members of their families, who had been informed of their risk of inheriting the disease and visited annually; but their table suggests that the fertility of those at high risk must have been reduced by about two thirds. The less intensive approach used in advising the men and women in the present survey suggests a reduction by about a half. In time such a reduction in the birth frequency throughout the population would reduce the prevalence of the disorder to much less than half of the present figure.

The general relationship for a dominant disorder between birth frequency (or incidence at birth) of heterozygotes (I), the mutation rate $(M)$, and the relative reproductive fitness $(F)$ is given by the expression $I=\frac{2 M}{1-F}$. The values of $I, M$, and $F$ are not known for Huntington's chorea. Direct estimates of the mutation rate for Huntington's chorea are unreliable. It is just the cases due to fresh mutation that are likely to be missed. Many clinicians are reluctant to make the diagnosis without a family history, and the diagnosis in a patient affected by fresh mutation is often made only retrospectively if and when he has an affected child. But in Britain the prevalence of the disorder as recorded in the more thorough studies is between 4.5 and 10 per $100000 .^{38-11}$ The true prevalence with complete ascertainment may, perhaps, be taken as nearer to the higher figure. The mean duration of illness from clinical diagnosis to death is about 12 years. ${ }^{12}$

The mean life expectation of the general population born in Britain in the 1930s is about 60 years. Therefore the prevalence of 1 in 10000 in the total population indicates a five times greater birth frequency (I) of gene carriers-that is, about 1 in 2000 (an underestimate to the extent that gene carriers die before developing the disease and so do not contribute to the prevalence). If one assumes, for example, a mutation rate (M) of 1 in 40000 , this implies, from using the formula given above, a relative reproductive fitness $(\mathrm{F})$ in the past of about 0.9 , and that only one case in 10 is due to fresh mutation. Two estimates of relative fertility have been close to $0 \cdot 9 .^{13} 14$ In a population where the birth rate is close to replacement rate this implies that each mutant gene on average survives 10 generations before disappearing.

The introduction of genetic counselling for the children of patients does not affect the incidence of births affected by fresh mutation or the reproductive fitness of patients affected by fresh mutation. But it will substantially reduce the persistence of the mutant gene to grandchildren and later descendants. Given that the population is static, that the reproductive fitness for patients affected by fresh mutation is $0 \cdot 9$, and that all children of patients affected by fresh mutation can be told of their risk, the effect would be to reduce the birth frequency in a few generations from 20 times the mutation rate to only 5.6 times the mutation rate,

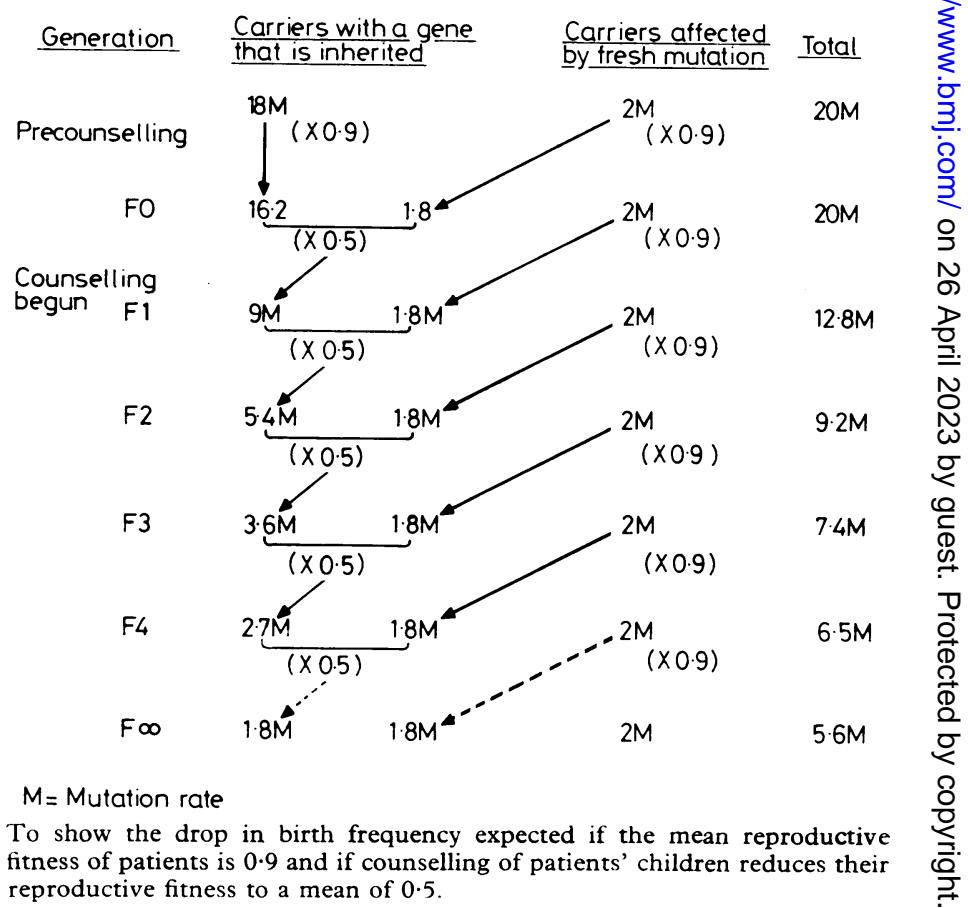


and the prevalence to less than a third of the present figure (fig). If, however-as some would maintain ${ }^{15}$-the proportion of cases due to fresh mutation is even less than 1 in 10 and the relative reproductive fitness of patients is more than 0.9 (perhaps even greater than 1.0 in recent centuries ${ }^{10}$ ) the reduction in the birth frequency and future prevalence of the disorder would be correspondingly greater.

Estimates of the effect of genetic counselling usually assume that those offspring at risk who have in fact inherited the gene for the condition behave similarly in their decisions on family planning to those who have not done so. ${ }^{3} \mathrm{We}$ have little information on this point as most of those at risk are too young to have developed the disorder; but, of the 21 consultands at the genetic clinic who had not started their families before they learnt of their risk, two have developed the disorder and neither has children. A further four have symptoms suggestive of the disorder; two have had no children; and two have each had two children. The expected number of children of these six consultands is $10 \cdot 1$, and their relative fertility is therefore close to that of the whole sample.

The full potential of genetic counselling for the prevalence of the disorder may be achieved more easily if those interested in Huntington's chorea can maintain at least outpatient contact with the family members who are at risk. The evidence from both the Welsh and the present study has led one of the authors $(\mathrm{MB})$ to provide a special follow up service for families with Huntington's chorea at a genetic clinic at the National Hospital. A few other such clinics at appropriate places in Britain would be highly cost effective, and there should be ready access to such clinics. Clearly, however, much may be achieved just by informing the offspring of patients of the risk to their children.

Within a generation methods will probably be found of detecting gene carriers before they develop the disease-for example, by a close linkage to a DNA fragment polymorphism. This will permit normal fertility of those who have not inherited the gene, and probably further reduce the fertility of those who know that they carry the gene and that the risk to their children is 1 in 2 and not 1 in 4 . Thomas has recently discussed the difficulties such a discovery would present, ${ }^{16}$ and we much hope that at the same time a line of treatment, even if only palliative, will be discovered that will give some reassurance to those destined to develop the disease.

We are indebted to the consultants at the National Hospital for Nervous Diseases for access to their patients' families and to Dr Richard Pratt, who reviewed the case notes. We also thank the family doctors of the patients and the genetic clinic consultands for advising us whether a visit was contraindicated.

Requests for reprints to: Dr M Baraitser, Clinical Genetics Unit, Institute of Child Health, 30 Guilford Street, London WC1N $1 \mathrm{EH}$.

\section{References}

${ }^{1}$ Carter CO. Monogenic disorders. F Med Genet 1977;14:316-20.

${ }^{2}$ Harper PS, Tyler A, Smith S, Jones P, Newcombe RG, McBroom V. Decline in predicted incidence of Huntington's chorea associated with systematic genetic counselling and family support. Lancet 1981 ;ii:411-3.

${ }^{3}$ Harper PS, Tyler A, Walker DA, Newcombe RG, Davies K. Huntington's chorea: the basis for long term prevention. Lancet 1979;ii:346-9.

${ }^{4}$ Carter CO, Evans K. Counselling in Huntington's chorea. Lancet 1979; ii $: 470-1$.

${ }^{5}$ Office of Population Censuses and Surveys. Birth Statistics, England and Wales 1979. London: HMSO, 1966.

${ }^{6}$ General Register Office. Census England and Wales, 1961: fertility tables. London: HMSO, 1966.

7 Office of Population Censuses and Surveys. Marriage and divorce statistics, England and Wales 1974. London: HMSO, 1977.

${ }^{8}$ Caro A. The prevalence of Huntington's chorea in an area of East Anglia. f R Coll Gen Pract 1977;27:41-5.

- Bolt JM. Huntington's chorea in the west of Scotland. Br $\mathcal{F}$ Psychiatry $1970 ; 116: 259-70$

10 Stevens DL. Huntington's chorea: a demographic and clinical study. London: University of London, 1976. (MD thesis.)

11 Oliver JE. Huntington's chorea in Northamptonshire. Br f Psychiatry 1970; 116:241-53.

12 Hayden MR. Huntington's chorea. Berlin: Springer-Verlag, 1981.

13 Reed TE, Neel JV. Huntington's chorea in Michigan: selection and mutation. Am F Hum Genet 1959;11:107-36.

14 Wendt GG. The fertility of patients with Huntington's chorea. Proceedings of the Second International Congress of Human Genetics. Vol 2. Rome: Excerpta Medica, 1963.

15 Shaw M, Caro A. The mutation rate to Huntington's chorea. $\mathcal{F}$ Med Genet 1982;19:161-7.

16 Thomas S. Ethics of a predictive test for Huntington's chorea. Br Med $\mathcal{F}$ $1982 ; 284: 1383-5$.

(Accepted 25 November 1982)

\section{Clinical curio: "size by volume" ski boots}

Two winters ago I was in a local sports shop being fitted with new "size by volume" ski boots when a previous customer came in to say that after wearing the same make of boots with comfort for a day his feet became numb, as indeed they were, to pinprick and light touch from the ankles down. This suggested pressure on cutaneous nerves or general ischaemia affecting the pain transmitting A fibres. Despite this warning and despite the most careful fitting of the boots by the assistants (all expert skiers) I found that my feet were also numbone worse than the other-at the end of a day of comfortable skiing. I continued to ski for the rest of the week (in retrospect this was unwise), and while my fellow sufferer's feet apparently recovered in six weeks mine are still not normal two years later. I assume that his axons suffered transient damage while mine degenerated. Last winter I again skied abroad with the inner boot reduced to take direct pressure off cutaneous nerves at the instep and medial malleolus. My feet, whose sensory recovery had proceeded in fits of quiescence and starts of uncomfortable paraesthesia, were set back somewhat in their recovery by this week's skiing. This autumn, on feet still suffering occasional paraesthesiae but with apparently normal sensation, I walked briskly round Stockholm for three hours on a conference afternoon when it seemed that the book of abstracts would suffice. Retribution came in the form of progressively severe burning pain in the distribution of the original numbness, which eventually forced me to rest. I think this was due to a steal of cutaneous blood by the muscles (despite normal ankle pulses and an ankle/brachial systolic index of 1.5 in each leg) leading to peripheral nerve ischaemia.

The design and concept of the ski boot in question are pleasing, but they would seem to need more research with multiple pressure sensors telemetering information from skiers' feet during a full day's skiing, including standing around and sitting in chair lifts. What happens to cutaneous blood flow in a limited volume boot when the foot swells? Is arteriolar pressure exceeded? Reliance on discomfort is clearly unreliable as a monitor for nerve damage, and anyway as anyone who has been on a ski bus at the end of a day's skiing knows ski boots and discomfort go together like ham and eggs. Now that the skiing season is here have the sports medicine specialists any help to offer on ski boots and nerve damage?-GAVIN D SMELLIE, consultant surgeon, Glasgow.

Is there any health hazard to children who drink milk from bottles where the tops and some milk have been removed by birds?

Several species of wild or garden birds, especially blue-tits, pierce milk bottle tops and drink a portion of the cream. As this procedure probably requires the expenditure of a lot of energy from the bird non-healthy or diseased birds would probably be incapable of this exercise. It would be possible to propose a list of theoretical hazards, such as the transmission of Salmonella typhimurium, Chlamydia psittaci, influenza viruses or arboviruses, some of which would necessitate the deposition of bird faeces into the milk bottle. To be realistic, however, the risk from healthy birds is probably negligible.J R WALTON, senior lecturer, Liverpool. 